\title{
A violência sistêmica e autoexplorativa do empresário de si: o paradoxo da liberdade no ethos neoliberal e o adoecimento psíquico na sociedade do cansaço
}

Laura Henrique Corrêa ${ }^{1}$

\section{RESUMO}

O ethos neoliberal está presente na economia, nas relações sociais, e também em nosso corpo, nas nossas mentes. Essa maneira de ser que na contemporaneidade deixa de ser repressiva e torna-se produtiva, nos afeta e nos constitui. Nesse contexto o presente estudo pretende estabelecer aproximações sobre as exigências laborais na contemporaneidade e o adoecimento psíquico. Para alcançar esse objetivo será elaborado um ensaio teórico com base no pensamento do filósofo Michel Foucault e seus desdobramentos contemporâneos. Como procedimento metodológico utilizou-se a revisão de literatura, buscando dar notícia de como constituímos a maneira de ser (ethos) em uma organização social que privilegia vertentes de mercado (neoliberal) pela produção de novos corpos dóceis autoexplorativos (empresariamento de si). Esse delineamento leva a uma hipótese de liberdade como objeto de consumo (paradoxo), a desconsideração dos padrões condicionantes da ação humana (violência sistêmica) que podem estabelecer bases para o adoecimento psíquico através do esgotamento e exaustão dos trabalhadores em uma sociedade que exige desempenho constante.

Palavras-chave: Foucault; Violência sistêmica; Trabalho; Corpos dóceis; Exaustão.

${ }^{1}$ Mestranda em Gestão Pública e Sociedade no Instituto de Ciências Sociais Aplicadas da Universidade Federal de Alfenas, campus Varginha - MG. E-mail: correalaura@hotmail.com. 


\begin{abstract}
The neoliberal ethos is present in economics, in social relations, and also in our body, in our minds. This way of being that in contemporary times ceases to be repressive and becomes productive, affects us and constitutes us. In this context the present study intends to establish approximations on the labor demands in contemporaneity and the psychic illness. To achieve this goal a theoretical essay will be elaborated based on the thinking of the philosopher Michel Foucault and his contemporary developments. As a methodological procedure we used the literature review, seeking to give news of how we constituted the way of being (ethos) in a social organization that privileges (neoliberal) market strands by the production of new self-explored docile bodies. This outline leads to a hypothesis of freedom as an object of consumption (paradox), the disregard of the conditioning patterns of human action (systemic violence) that leads to psychic illness due to the exhaustion and exhaustion of workers in a society that demands constant performance.
\end{abstract}

Keywords: Foucault; Systemic violence; Work; Docile bodies; Exhaustion.

\title{
1 Introdução
}

$\mathrm{P}$ ensar uma existência produtiva característica de nossos tempos pode ser um ponto norteador para analisar a origem das doenças psíquicas relacionadas ao trabalho. Esses novos contornos da atividade laboral parecem consumir todas as possíveis fontes de recursos, por via de um controle bastante eficiente: o próprio ser. Uma maneira de ser que enfatiza o binômio desejo-consumo e afeta mais do que os corpos, atuando através de uma autoexploração constante, uma eficiente alavanca para a economia de mercados, visto que as atividades valorizadas são as que possuem alguma utilidade, assim, o ócio como tempo livre desaparece da vida desse capital humano produtivo.

Weber (2013) faz uma conexão entre os aspectos materiais e 
éticos quando relaciona o conceito de vocação profissional como uma base motivacional para o sistema capitalista, focalizando o olhar na ética formada, que valoriza o trabalho e a busca pelo aumento de posses como um dever moral. Então trabalho e sucesso econômico se tornam parte do caminho para a salvação, uma valorização religiosa do trabalho que engendra a aceitação voluntária de práticas da moderna cultura capitalista. Um espírito que incorpora a ética religiosa protestante de “vocação e devoção ao trabalho, que é, como vimos, tão irracional” (Weber, 2013, p. 78) mas que em grande medida continua sendo motor da cultura de acumulação e de aceitação do sofrimento como inerente ao processo de purificação.

Esse saber econômico como motivação psicológica engendrado na totalidade da ação humana é, na prática neoliberal, a apreciação de si na planilha de custos. O estudo, a saúde, o trabalho, entre outros aspectos formam um, tornam-se componentes desse capital humano que deve ser bem administrado pelo empresário de si mesmo no jogo do mérito e culpa dessa união vida-economia, em uma análise que desconsidera as pré-condições econômicas e sociais dos indivíduos. Tais aspectos fazem referência a liberdade como objeto e a violência sistêmica na qual estamos inseridos e construímos a cada dia na desvalorização das dimensões humanas de ação pela palavra, ócio, tempo livre, entre outras.

Desta maneira parece razoável explanar argumentos acerca do modo de viver pessoal e social e o adoecimento psíquico_crescente, como esclarece Gadelha (2009, p. 182) quando enfatiza que as relações de sociabilidade se tornam frágeis, diminuem a capacidade de agenciamento entre pares que tornam possíveis novos modelos além dos estabelecidos pelo mercado, gera insegurança em um meio de concorrência extrema, ou seja, atua diretamente nos processos de subjetivação que fragmenta e homogeneíza. Essa elevação exponencial 
dos preceitos já aceitos voluntariamente, leva as pessoas à "passividade política e mesmo ao adoecimento psíquico", em um processo que observa o ser como um capital que necessita ser maximizado, dentro da governamentalidade neoliberal.

À vista disso, como ponto de impulso reflexivo foi utilizada a teoria foucaultiana e seus desdobramentos em contato com aspectos cotidianos, demonstrando como que conforme cada objetivo da sociedade as maneiras de controle das populações foram se moldando aos objetivos e desta maneira explana-se como o empresariamento de si serve aos ideais neoliberais. Para interligar os assuntos nesse pequeno ensaio teórico serão abordadas breves reflexões sobre o ethos, o neoliberalismo, os novos contornos dos corpos dóceis, a sociedade do cansaço e o consequente adoecimento psíquico, com o objetivo de fazer aproximações entre as exigências laborais na contemporaneidade e o adoecimento psíquico.

\section{Do ethos neoliberal ao cansaço: corpos dóceis em ação}

\subsection{Ethos}

Quem se entedia no andar e não tolera estar entediado, ficará andando a esmo inquieto, irá se debater ou se afundará nesta ou naquela atividade. Mas quem é tolerante com o tédio, depois de um tempo irá reconhecer que possivelmente é o próprio andar que o entedia. Assim, ele será impulsionado a procurar um movimento totalmente novo. [...] Comparada com o andar linear, reto, a dança, com seus movimentos revoluteantes, é um luxo que foge totalmente do princípio do desempenho.

(HAN, 2017, p. 35)

Uma ideia que precisa suportar o peso da experiência concreta para que não se torne mera abstração é o que Sennett (2009. p. 11) demonstra ao inserir conceitos filosóficos em conversação com o 
cotidiano. Deste ponto de apoio das análises da maneira de ser inserida no neoliberalismo, temos a percepção de que sempre estamos em falta com algo. Quando o trabalho vai bem, a família parece carecer de atenção e quando nos desdobramos, ainda resta encontrar um tempo para si, para os amigos, para o ócio. Sennett (2009, p. 69) infere que "a nova ordem impõe novos controles" o que torna confusa as relações com os valores que são atribuídos a si, sejam elas éticas ou coletivas.

De qualquer maneira estabelecer uma guerra constante consigo mesmo em busca do que não é admissível reconhecer como impossível, entrega os seres a um processo de autodestruição, degradação de si, que leva a dois caminhos de poucos prazeres: a produção desenfreada e o ócio culpado. Em uma espécie de "revolta contra a rotina" que retira a submissão direta e insere o controle, fisicamente descentralizado e que assume o risco do resultado, o tempo flexível se toma a aparência de uma liberdade enganosa, que pela desordem maximiza o poder nos trabalhadores (SENNETT, 2009, p. 117).

No primeiro caminho uma produção constante e sem limites, o atendimento de tudo e de todos é sempre a prioridade. Corpo e mente exaustos sempre tem um novo empreendimento a realizar. Já no segundo o ócio é alavanca da culpa, onde atividades não produtivas são desvalorizadas ao ponto de perder o sentido. Não é difícil observar essas características no meio social, uma simples questão bastante comum denota como estamos tão acostumados a esta maneira de ser. Quem nunca ouviu ou pronunciou: Essa atividade serve para quê? Como se fosse natural que todas as ações humanas tivessem o imperativo instrumental de servir a algo.

Já o contrário também se mostra uma importante vertente de confirmação. Surgem estranhamentos no contato com a capacidade de produzir-se sem finalidade, seja pela arte, pela filosofia, com a música, enfim, o espanto de essencialmente não servir, a dimensão 
contemplativa distante do ser. Para esclarecer um pouco mais, entender o ócio se torna primordial. Ao longo dos tempos as palavras vão se ressignificando, se tornando mais identitárias de um movimento histórico social, tal fato se comprova pelo esforço de autores que por páginas se dedicam a explanar significados transmutados de origem na dilatação do tempo.

Segundo Carvalho (2017, p. 31) o ócio grego não é o mesmo do contemporâneo, tal como a significação da escravidão grega não tem a mesma conotação da moderna. $\mathrm{O}$ ócio para os gregos se findava em um tempo livre, mas o livre fazia referência à liberação das atividades de subsistência. Atualmente a conotação negativa de ócio serve aos ideais de produtividade, onde a finalidade de consumo apenas para a subsistência seria o desmonte da mais-valia. Essa referência do tempo livre para a discussão e formação do ser é exatamente o ponto chave em toda a atividade formativa grega. Na perspectiva arendtiana formar o indivíduo para a pólis (cidade) seria a capacidade humana de passar a história para o futuro com o viés do inesperado. Um inesperado que para os meios produtivos seria a derrocada, e para os meios humanos a alavancada necessária para a emancipação. Não que o que chamamos de criativo e novo seja necessariamente conduzido ao caminhar em frente, em uma ideia de progresso, mas que o que se cria é exatamente o nada que se joga à sorte, expressão do ser, à não reprodução do que se está, um milagre (ARENDT, 2008, p. 161).

$\mathrm{Na}$ contemporaneidade a formação do homem para atuar no meio social é bastante diferenciada da descrita acima, dando forma a um ethos (maneira de ser) que aparece com o neoliberalismo em uma ideia de ser livre, sendo competitivo, pois em tudo deve-se ser bem-sucedido: em casa, na família, no trabalho, enfim tudo em raciocínio custo benefício. Competição e sujeição ao imperativo do mercado. Os motivos para essa ênfase podem ser bastante diversificados e abrangentes, e não 
poderiam ser esgotados neste estudo, todavia o destaque é colocado sobre esse impulso mais forte a uma determinada maneira de ser que engloba uma certa caraterística menos plural do que é possível ser enquanto humanos.

Boltanski e Chiapello (2009, p. 42) descrevem esse processo como "incitações práticas à ação" que marcam esse novo ethos e, portanto, desqualificam aspectos que se referem às práticas tradicionais e normalizam "a generalização da disposição para o calculismo, a suspensão das condenações morais ao lucro e a arrancada do processo de acumulação ilimitada”. Alguns autores críticos da atualidade brasileira, como Marilena Chauí, também apontam o neoliberalismo como uma forma que força a redução da pluralidade à lógica empresarial. Para Chauí (2016) há em curso uma descaracterização da política por uma ênfase nos aspectos de mercado, com a sua efetividade no subjetivo representada pelo sufrágio positivo de gestores na política. Uma montagem ideológica sustentada pela transformação da economia, da sociedade e da política.

\subsection{Neoliberalismo}

Por falta de repouso nossa civilização caminha para a barbárie. Em nenhuma outra época os ativos, isto é, os inquietos, valeram tanto. Assim, pertence às correções necessárias a serem tomadas quanto ao caráter da humanidade fortalecer em grande medida o elemento contemplativo.

(NIETZSCHE, 2005, p. 177)

Longe de determinar uma relação de causa e efeito simplista, bem e mal, os apontamentos realizados buscam identificar transformações e ressonâncias sobre uma história do presente em camadas produzidas pelos saberes sociais nos diversos tempos. Essa 
tranquilidade da constituição de um homem histórico em movimento dentro de seu tempo faz referência a um neoliberalismo onde seria pouco efetivo compreendê-lo como forma de justificação e sustentação do capitalismo, mas sim como uma maneira de ser estar no mundo de indivíduos que neste tempo histórico-social buscam dar ênfase às relações de mercado.

Desta maneira, pode ser razoável inferir que todos os potenciais humanos serão aproveitados em prol do mercado, incluindo aí um impulso subjetivo que se impõe como a relação de interioridade que se transmuta em capital humano. Da necessidade da liberdade de mercado proposta pelo liberalismo, passando pela tentativa de um Estado de direitos para todos indicada no Estado de bem-estar social, houve uma alteração de contornos para essa nova forma (neo) de liberalismo, que se mostra mais voraz tanto quanto o mercado globalizado.

Em uma maneira liberal de agir ante às crises que os próprios modelos produziram, impulsiona-se a difusão atual do discurso neoliberal, onde a autocrítica de um sistema clássico que preservava o Estado para alguns setores, passa a ser a justificativa da falência do modelo, pois o Estado, na visão dos neoliberais, engendrou a falência do liberalismo e o Estado de bem-estar social é uma impossibilidade. Já para os neoliberais o monopólio, que representou em grande medida a principal crítica do sistema clássico e teve sua origem na ação inadequada do Estado, que continuou atuando em alguns setores e, ainda, pela não focalização da ação estatal nos sistemas legais para o mercado. Nessa perspectiva a solução apontada seria a organização de todo o sistema em ações ordenadas pelo jogo concorrencial, em um mercado que é capaz de se regular econômica e socialmente. Então o mercado centralizado no livre comércio passa a ser focalizado na competitividade, e a sociedade de produtores de mercadorias passa a ter características de consumidores permanentes. Não que foram 
excludentes produtores e consumidores, mas que agora há o englobamento de todos como consumidores, porém com diferenciações de acesso. O quadro 1 aponta algumas das características de uma política liberal e social diante da neoliberal:

Quadro 1: Algumas características da política liberal, social e neoliberal.

\begin{tabular}{|c|c|c|}
\hline POLITICA LIBERAL & POLÍTICA SOCIAL & $\begin{array}{l}\text { POLÍTICA } \\
\text { NEOLIBERAL }\end{array}$ \\
\hline Economia autoregulatória & Economia social & $\begin{array}{l}\text { Economia social de } \\
\text { mercado }\end{array}$ \\
\hline $\begin{array}{lcc}\text { Estabelece a garantia } & \text { de } \\
\text { propriedade } & \text { livre } & \text { do } \\
\text { soberano } & & \end{array}$ & $\begin{array}{l}\text { Reparte acesso aos bens e } \\
\text { consumo }\end{array}$ & $\begin{array}{l}\text { Estabelece a } \\
\text { concorrência e o jogo de } \\
\text { diferenciações para } \\
\text { acesso }\end{array}$ \\
\hline $\begin{array}{ll}\text { Liberdade } & \text { econômica } \\
\text { individual } & \text { produz a } \\
\text { economia } & \\
\end{array}$ & $\begin{array}{l}\text { O social é o contrapeso dos } \\
\text { processos econômicos }\end{array}$ & $\begin{array}{l}\text { O social produz a } \\
\text { economia }\end{array}$ \\
\hline $\begin{array}{ll}\begin{array}{l}\text { Acesso privado às } \\
\text { condições básicas }\end{array} & \\
\end{array}$ & $\begin{array}{l}\text { Socializa o acesso a } \\
\text { condições básicas }\end{array}$ & $\begin{array}{l}\mathrm{O} \text { processo de mérito } \\
\text { determina o acesso. }\end{array}$ \\
\hline $\begin{array}{l}\text { Mantém com } \\
\text { proprietário os } \\
\text { crescimento }\end{array}$ & $\begin{array}{l}\text { Distribui os frutos do } \\
\text { crescimento }\end{array}$ & $\begin{array}{l}\text { Centraliza os frutos do } \\
\text { crescimento }\end{array}$ \\
\hline Capitalização individual & $\begin{array}{l}\text { Capitalização atuante no } \\
\text { mercado }\end{array}$ & $\begin{array}{l}\text { Capitalização } \\
\text { generalizada }\end{array}$ \\
\hline
\end{tabular}

Fonte: elaboração própria. Dados: Veiga-Neto, 2013, p. 39.

Desse modo se pode inferir que algumas características do neoliberalismo são tomadas como pano de fundo do modo de viver e, portanto, estão atuantes na constituição da formação dos seres contemporâneos: a liberdade exercitada pela competição, os processos econômicos enfatizados, e a busca por regulação e controle permanente. Esse movimento dá a característica do neoliberalismo, como algo que “produz e consome liberdade” fazendo com que a liberdade seja também "um objeto de consumo" (VEIGA-NETO, 2013).

Para esse realce do consumo, a fábrica disciplinar administrada 
se reformula em empresa subjetiva gerida, as vendas são précondicionantes das mercadorias e dos postos de trabalho, e o consumir, toma contornos de pertencimento ao mundo no meio social.

Assim os pré-requisitos dos trabalhadores sofrem alterações com a sobreposição da inovação, criatividade, flexibilidade, à produção. Os espaços fabris se alargam abrangendo os espaços privados $\mathrm{e}$ ultrapassando as jornadas de trabalho, pois o trabalhador é responsável pelo seu constante aprimoramento, sua carga de informações e acontecimentos. No trabalho imaterial, a vigilância do corpo é secundária ao uso das informações para a multiplicação do capital. A reprodução é contraposta à inovação e a ação produtiva em rede é sempre mais lucrativa nessa alteração do "capitalismo industrial” para o “capitalismo cognitivo” (VEIGA-NETO, 2013, p. 41-46).

De qualquer maneira, tanto na política liberal quanto na social, o Estado era predominante no processo de governar os seres. O que muda com os preceitos neoliberais é que as empresas ganham uma abrangência nunca antes alcançada e, ainda, apoiada pela identidade popular, pois tanto o privado quanto o público parecem estar tão unidos que desempenham um papel único e o indivíduo também é empresário, de si.

Segundo Chauí (2016) um dos sintomas que dão concretude às argumentações de que o Estado, as instituições e os seres são observados pela ótica empresarial é a análise dos conflitos dentro das instituições. Nelas os processos naturais à pluralidade passam a não ser manifestados, não operando com contradições, utilizando-se de mecanismos excludentes (demissões) ou legais (processos indenizatórios) para a operação da homogeneidade. Uma normalização onde o desviante é eliminado do espaço se inferior hierárquico e judicializado se influente. Ocorre a ênfase na judicialização das interações humanas, políticas, um efeito da transformação do Estado em empresa e do indivíduo em 
empresário de si.

Os neoliberais acreditam no princípio da concorrência como regenerador social, enfraquecendo instituições, leis e indivíduos, onde todos estão submetidos as leis de mercado, modelando a organização do sistema social sob a lei da concorrência. O Estado apenas garantiria as condições de concorrer. A sociedade ordenada para e pelo mercado.

Nesse contexto o mercado que exigia a não intervenção do governo no modelo liberal, passa a gerir todo o princípio interno de regulação do Estado no modelo neoliberal, o que fica bastante evidente quando Foucault expressa o problema do neoliberalismo como "saber como se pode regular o exercício global do poder político com base nos princípios de uma economia de mercado"(2008, p. 181). Esse é o projeto do neoliberalismo: fazer com que a economia política se transforme em princípio crítico para a limitação do poder do Estado. Foucault esclarece melhor neste trecho do livro nascimento da biopolítica:

[...] o instrumento dessa política social, se é que podemos chamar isso de política social, não será a socialização do consumo e da renda [...] Vai se pedir à sociedade, ou antes, à economia, simplesmente para fazer com que todo o indivíduo tenha rendimentos suficientemente elevados, de modo a que possa, seja diretamente e a título individual, seja pela intermediação coletiva das sociedades de ajuda mútua, se garantir por si, mesmo contra os riscos que existem, ou também contra essa fatalidade da existência que são a velhice e a morte, a partir do que constitui sua própria reserva privada [...] É o que os alemães chamam de política social individual, em oposição à política social socialista. Trata-se de uma individualização da política social pela e na política social, em vez de ser a coletivização e a socialização pela e na política social. Em suma, não se trata de assegurar aos indivíduos uma cobertura social dos riscos, mas de conceder a cada um, uma espécie de espaço econômico dentro do qual eles possam assumir e enfrentar os riscos (FOUCAULT, 2008, p. 150).

Um Estado submetido ao jogo de mercado determina a cada indivíduo a lógica concorrencial, atuando na promoção do modelo. Em suas instituições há a aplicação do modelo econômico empresarial, os 
patrimônios são observados pelo prisma de um ativo que necessita ser capitalizado. Educação, segurança e seguridade social como objetos de livre comércio delimitados ao privilégio. A política social é o crescimento econômico e esse deverá permitir que cada indivíduo por seu esforço construa seu seguro individual.

Nesse modelo indivíduo-empresa o que ressalta é o valor mercantil das vidas, que constrói uma ponte estabelecida pela ameaça do desamparo constante na assimilação individual. Um sujeito empreendedor que assume os riscos e, portanto, incorpora por um lado o medo e por outro um desejo constante de consumo no campo da competitividade social e pessoal. Essa racionalidade neoliberal busca "tratar" os transtornos sociais e elevar cada humano ao seu exponencial, e suas consequentes responsabilidades, seus próprios riscos (PASSETI, 2015, p. 16).

Essa inserção do risco como algo desnorteante e deprimente (SENNETT, 2009, p. 9), insere pressão ao indivíduo que está cada vez mais desamparado pelos mecanismos tradicionais de organização laboral, tais como normas, regulamentos e leis, pois o tempo e o espaço são estrategicamente desregulados. Então o risco "se torna uma necessidade diária enfrentada pelas massas" (SENNETT, 2009, p. 95) engendrando o medo que leva à flexibilização, resiliência e maximização dos trabalhadores, que não dispondo de garantias dentro dos aspectos de subjetivação laboral, convivem com apreensão e ansiedade constante.

\subsection{Os novos contornos dos corpos dóceis}

Descrédito no presente e futuro incerto parecem ser as marcas corpóreas e subjetivas deixadas pelo não cumprimento das promessas de prosperidade para todos. Uma insegurança coletiva que coloca descrédito nas bases que conhecemos: o Estado que articula e garante o 
bem-estar e o mercado de bens e consumo materiais e imateriais. Esse binômio de representação-bem-estar e desejo-consumo constroem as linhas de mandamento dos corpos sociais contemporâneos.

Foucault (2014) descreve um caminho, que inicia na soberania onde o sangue determinava a realeza e a manutenção do poder se dava pela via da barbárie exposta conforme os designíos do soberano. Sua atuação era pela via do fazer morrer ou deixar viver. Essa maneira de soberania violenta de sofrimento público, ganhou contornos mais sutis quando a população começou a se comover e se horrorizar com as atividades reais. Essa mudança na aceitação comunitária ensejou uma alteração nas formas de governo, colocando sua atuação não mais pelo fazer morrer e deixar viver, mas sim pelo seu contrário: fazer viver e deixar morrer. Esses discursos pautados pela positividade trouxeram duas tecnologias de poder implementadas nos governos que foram se alterando ao longo dos tempos sempre dentro do fazer viver e deixar morrer.

A primeira é a biopolítica como uma maneira de utilizar dados informativos do Estado, a estadística, como fonte de organização do corpo bios, atuando no controle de endemias, demografia, entre outras, que determinam a segurança populacional pela via bio, produzindo o efeito do fazer viver para algumas partes populacionais. As que são deixadas a morte pouco são visualizadas. Já a segunda é a governamentalidade, uma maneira administrativa de gerir que coloca regras e instituições para o controle e silenciamento dos corpos, exercício e tempo controlado, refletindo em suas subjetividades pela sensação de vigilância constante. Essa atuação sutil pode ser observada pelo sistema de regras humanas produzidas e suas determinações. Escolas, presídios, casas psiquiátricas, albergues, ganham o mesmo tom, construindo clausuras com base no determinado normalizado no parâmetro do corpo produtivo e consumista. Assim os que não se 
encaixam nas regras parecem invisíveis socialmente: os desescolarizados, os privados de liberdade, os loucos, entre outros, que constituem a “carne barata”, não produtiva.

Com formas de governamentos cada vez mais expansivos e abrangentes, a sociedade passa a ser descrita por Deleuze (2000) pela via do controle. Nela a subjetividade ganha destaque, pois agora captura potencialidades, atua nos desejos e principalmente faz com que o ser acredite não ter nenhum condicionamento além do livre arbítrio. Essa mistura que se faz pelo descredito atual e um histórico de medo da barbárie soberana, de docilização dos corpos e controle das subjetividades, em um terreno onde a produção e o consumo são pilares, temos o crescimento de um ethos (maneira de ser) neoliberal em novos contornos.

Sem abandonar o medo (ameaça de passar a grupo invisível) e o corpo dócil (obediente e desejante), as relações de trabalho contemporâneas se voltam para o conhecimento e os afetos. Em linhas reelaboradas as novas exigências laborais se pautam em: criatividade permanente, resolução de problemas de maneira ágil, flexibilidade, entre outras que fazem com que o ser procure em si traços determinados pelo ambiente neoliberal e se culpe pelas ausências (TARRÉS et.al, 2016, p. 220). Esse imperativo produz o empresário de si, o trabalhador que se empenha apaixonadamente e sem descanso busca atingir uma meta nunca alcançável ou imensurável, trazendo para si essas responsabilidades. Qualquer inadequação justificaria a sua retirada no meio laboral e entrada no grupo invisível.

Nesse elo formado entre a maneira de ser neoliberal e a governamentalidade, que unifica as formas de dominação e as técnicas de si, nasce esse efeito humano do empresariamento de si, que Ambrósio (2012, p. 58) apresenta como a formação do capital humano que é produzido para que se possa competir cada vez mais vorazmente, 
tomando "como princípios éticos de constituição de si os enunciados propagados pela gerência, tornando suas vidas uma aplicação de um tipo de capital" um capital que se acumula conforme os investimentos que realiza, sua competência, eficiência, seus resultados. Essa formulação do homem empresário de si dentro do conceito neoliberal de economia é demonstrada por Foucault:

\footnotetext{
O homo economicus é um empresário, e um empresário de si mesmo. Essa coisa é tão verdadeira que, praticamente, o objeto de todas as análises que fazem os neoliberais será substituir, a cada instante, o homo ecomomicus parceiro da troca por um homo economicus empresário de si mesmo, sendo ele próprio seu capital, sendo para si mesmo a fonte de sua renda (FOUCAULT, 2008, p. 311).
}

A alteração do homem da produção para o investidor de si como capital humano, um ser com resultados excepcionais empreendendo o menor recurso, eficiência máxima e conduta preventiva, são algumas das características bastante nítidas que adentram a vida dos seres. Fazer como Sennett (2009) e colocar a teoria à prova da experiência, observando os trabalhadores nas diversas áreas é bastante útil para ratificar tais hipóteses de realidade. Em vendas cobra-se simpatia constante, atendimento de metas quantitativas individuais e cooperação em um ambiente competitivo de trabalho; em saúde o atendimento a um número predefinido de pacientes; em educação a quantificação de publicações e índices de produtividade; entre inúmeras outras exigências que coloca objetivos muitas vezes inalcançáveis.

Como ser simpático sempre? Como competir com metas individuais e cooperar no trabalho? Como atender com qualidade um grande número de pacientes em tempo cronometrado? Como o conhecimento pode ser avaliado pelo número de publicações? Essas são apenas algumas das questões que podem ser indicadoras de uma espécie de exigência aos parâmetros do mercado das questões afetivas, uma 
homogeneização de capacidades cognitivas e relacionais. Em última análise, ao contrário do discurso, o que menos se procura é a satisfação, seja dos trabalhadores ou dos clientes, para a manutenção do consumo.

\subsection{A sociedade do cansaço}

A sociedade do século XXI não é mais a sociedade disciplinar, mas uma sociedade de desempenho. Também seus habitantes não se chamam mais "sujeitos de obediência”, mas sujeitos de desempenho e produção. São empresários de si mesmos.

(HAN, 2017, p. 22)

Para Han (2017, p. 8) cada época carrega consigo uma enfermidade inerente à sua maneira de viver. Esse ethos que se manifesta mental e corporeamente também engendra percepções, reconhecimentos, enfim, condutas sociais nos tempos. Nessa perspectiva, o que para os modernos representou uma época imunológica, com base na imanência bacteriológica onde há o reforço de procedimentos de eliminação dos perigos, construiu-se uma divisão nítida entre o fora e o dentro, que também se refletiu na sociedade em procedimentos de ataque e defesa, que tem como ponto mais evidente de manifestação as duas guerras mundiais que eclodiram no século XX.

Com o fim dessa época representada pela descoberta e disseminação dos antibióticos, o olhar de ação para a eliminação perde força em um pano de fundo que ascende à economia de mercado, que se expande juntamente com as táticas de sobrevivência neste, conformando uma mudança de paradigma, que se inicia aproximadamente após a guerra fria (HAN, 2017, p. 10). Desta maneira, pode-se observar que o desenho da contemporaneidade traz o apontamento de uma "violência neuronal" que é característica de um tempo social que constrói a perda de ênfase na lógica imunológica negativa de violência eliminatória, para 
a lógica superprodutiva positiva de violência, que culmina no esgotamento, exaustão e sufocamento do ser, como assevera Han:

\begin{abstract}
A violência neuronal não parte mais de uma negatividade estranha ao sistema. É antes uma violência sistêmica, isto é, uma violência imanente ao sistema. Tanto a depressão quanto o transtorno do déficit de atenção e hiperatividade (TDAH) ou a síndrome de Bournaut (SB) apontam para um excesso de positividade. A SB é uma queima do eu por superaquecimento, devido a um excesso de igual. O hiper da hiperatividade não é uma categoria imunológica. Representa apenas uma massificação do positivo (HAN, 2017, p. 21).
\end{abstract}

Nesse contexto a forma de execução da violência neuronal, tem alterações em sua forma de operação: o que antes era uma operação direta, negativa, violenta e explicitamente buscava eliminar os riscos, transforma-se em operação sutil, positiva e potencializa sua violência que agora é mais abrangente no ser. O que antes levava às doenças do corpo, atualmente leva a um "infarto psíquico" pela via da exaustão.

Para delinear melhor esses conceitos, pode-se compreender como eles atuam socialmente. Foucault (2014) delineou a sociedade disciplinar como aquela que atua na docilização dos corpos, produzindo o efeito de silenciamento político e reprodução. Tais características vão de encontro com as necessidades do período de industrialização. Esse mundo especialista em disciplinas construiu uma sociedade disciplinar que na perda de sentidos e apatia preparou as bases de aceitação de um processo de condução de condutas. Um indivíduo preso na identidade produtiva e, portanto, engendrado na subjetividade economicamente produtiva e politicamente submissa.

O deslocamento da ideia de produção de corpos dóceis (FOUCAULT, 2014, p. 133-189) para a condução das condutas (DELEUZE, 2017, p. 223-230) marca o direcionamento de uma nova sociedade, a do controle. Essa organização social não mais tem o ímpeto de produzir apenas o corpo preso a atividade e os silenciamentos, tem um projeto 
mais integrado, atingindo as subjetividades.

Han (2017) vai ainda mais além, para o autor tanto a sociedade disciplinar quanto a de controle são baseadas na linha negativa, de eliminação, observando que a sociedade do desempenho está caminhando cada vez mais para esse distanciamento, atuando pela positividade. Atuando por um certo desejo de maximizar, onde em todo local se observa uma maneira de obtenção de rendimentos, há um impulso ao ser mais rápido, produtivo e flexível às exigências de mercado. Novamente se adequando aos contornos_sociais, hoje neoliberais.

A racionalidade neoliberal estabelece que o mercado não é natural, mas que apenas com ele é possível crescer e o Estado tem o dever de criar condições para que as pessoas se tornem competitivas. Em uma análise não apenas econômica, o neoliberalismo produz a condução da conduta do outro atingindo a condução da própria conduta através da subjetividade que se empenha na maximização de si.

Para essa racionalidade socialmente ganhar corpo e neutralizar resistências, a produção da subjetividade é fundamental, pois para os preceitos de economia de tudo, é necessário o sujeito de interesse, competitivo e empresário de si mesmo: o homem como capital que deve a todo tempo aumentar seu capital, inclusive humano. A disciplinarização, o controle e o desempenho, em diferentes medidas, porém bastante atuantes, deixam de lidar com as resistências, passando a ter sujeitos imobilizados pela resiliência, com subjetividades flexíveis e conformadas. Um cidadão que se autocontrola, que monitora a si e aos demais, combinando um certo ativismo eletrônico contínuo (PASSETI, 2015, p. 15).

Desta maneira o sujeito do desempenho está mais livre da instancia externa que o explora e é mais submisso a si mesmo, sendo isso que o distingue do sujeito da sociedade disciplinar, que tinha a obediência e silenciamento como características fundamentais. 
Entretanto é imperioso salientar que a retirada da instância dominadora não determina sua liberdade, pois este passou antes pela experiência do controle de condutas, onde recebeu uma grande carga de técnicas de si, que podem ser vistas tanto como uma prescrição social do correto quanto pela determinação social e política a que os indivíduos estão condicionados.

Assim liberdade e coação se coincidem. Este ser de desempenho tem duas opções: ou se submete à liberdade coercitiva ou à livre coerção de maximizar o desempenho. Na segunda opção, a exaustão do excesso de atividade produtiva e a pressão de desempenho satisfatório constante culmina em um auto exploração que produz como efeito patologias (HAN, 2017, p. 29-30). Nesse entendimento a depressão é observada como a pressão do desempenho, a Síndrome de Bournaut como alma consumida, entre outras que tem em comum a característica dessa nova forma de coerção, onde o senhor é escravo do trabalho, explorador e explorado, agressor e vítima.

Uma configuração aparentemente mais eficiente economicamente que uma exploração de um outro, caminhando tangencialmente ao sentimento de liberdade e agregado à inexistência da figura a se combater. Some o dominador, cala-se as resistências e intensifica-se a resiliência. Essa fórmula neoliberal quase certa de um esgotamento humano sistêmico, carrega em sua sutileza, patologias de sofrimento social pela via da auto exploração, tendo como base uma liberdade paradoxal, onde o indivíduo se maximiza pela esperança, crença e culpa de ser livre, por estar silenciosamente condicionado a estruturas coercitivas habilidosas, que atuam desde a formação do ser.

O crescimento das doenças psíquicas e a constatação desse perfil de liberdade e responsabilidade de desempenho que ignora os condicionantes pessoais e sociais, inerente ao empresariamento de si e a um ethos neoliberal de valorização econômica e consumo, nos apontam 
um sujeito direcionado à maximização e a exaustão, em uma estrutura violenta de difícil escape, onde o adoecimento psíquico é patologia do modo de viver, em liberdade paradoxal.

\section{Considerações finais}

Vidas que parecem ser regidas por uma relação de desejo e consumo, na qual a economia de mercado parece ser primordial e essencial à manutenção do que construímos como a maneira de viver desse tempo. Com uma constituição do ser bastante interligada aos preceitos econômicos priorizados na contemporaneidade, o indivíduo de desempenho exponencial, competitivo e sempre bem-sucedido passa a habitar os ideais subjetivos dos trabalhadores, tornando-os empresários de si mesmos.

Em busca de metas intangíveis constantes, sejam corpóreas ou afetivas, os empresários de si são levados à exaustão, em um mundo onde a utilidade tem valor e o descanso não é permitido. Nessa perspectiva os corpos dóceis ganham características subjetivas, de trabalho imaterial com exigências intangíveis e auto explorativas. Um novo contorno que coloca a vida pessoal imersa em perspectivas de desempenho constante, onde a luta de resistência ocorre dentro do próprio ser, exatamente onde coabita o funcionário e o chefe tirânico, em período integral.

Esse pano de fundo dos modos de viver trazem uma reflexão sobre uma violência sistêmica que desconsidera os condicionantes sociais e enfatiza aspectos afetivos impossíveis de serem alcançados, porém altamente sedutores ao mercado. Assim a liberdade também é vista como objeto de consumo neoliberal se apresentando como um paradoxo, pois aparentemente se é livre do dominador gerando 
responsabilidade e culpa e, ainda, se tornando escravo permanente do trabalho pela conformação de si mesmo.

Esse ser exaurido tem aceitabilidade desse modo de viver talvez pela via do medo de um sistema de exclusão criado, que determina corpos e subjetividades não produtivas como invisíveis, operando socialmente através da homogeneização de padrões de acordo com os ideais de mercado. Nesse contexto o ser comprimido, por si, pelo meio, exausto, culpado, morto pela violência da retirada de dimensões humanas, após muitas resiliências forçadas na superação de situações adversas constantes e mesmo permanentes, desenvolve o adoecimento psíquico como última ação, biológica desesperada em busca de apenas um respiradouro como alternativa para a sobrevivência.

A desilusão provocada pelo sonho do Estado de bem-estar social engolido na necessidade de sobrevivência que o mercado impetra, insere medo e exigências de melhor custo-benefício ao humano, agora considerado capital a ser maximizado. O ócio que representa o cuidado de si na relação consigo e com os outros tem pouco espaço e, quando ocorre, remete à culpa. Desta maneira a única consideração final possível seria manter a chama do questionamento acesa e permanente, interrogando como se constitui essa maneira de ser, a quem essa conduta serve e quais os efeitos sociais e individuais ela produz.

\section{REFERÊNCIAS}

AMBRÓZIO, Aldo. Governamentalidade neoliberal: disciplina, biopolítica e empresariamento da vida. Kénesis-Revista de Estudos dos Pós-Graduandos em Filosofia, v. 4, n. 08, 2012.

ARENDT, Hannah. Homens em tempos sombrios. Editora Companhia das Letras, 2008.

BOLTANSKI, Luc; CHIAPELLO, Ève. O novo espírito do capitalismo. WMF Martins Fontes, 2009. 
CARVALHO, José Sérgio Fonseca de; CUSTÓDIO, Crislei de Oliveira. Hannah Arendt: a crise na educação e o mundo moderno. São Paulo: Intermeios; FAPESP, 2017.

CHAUI, Marilena. Contra a universidade operacional e a servidão voluntária. In: Conferência de Abertura do Congresso da Universidade Federal da Bahia- 14 de julho de. 2016.

DELEUZE, Gilles. Mil platôs: capitalismo e esquizofrenia. Editora 34, 2000.

FOUCAULT, Michel. Nascimento da Biopolítica: curso dado no Collège de France (1977-1978). São Paulo: Martins Fontes, 2008.

Vigiar e punir: nascimento da prisão. Petrópolis, RJ: Vozes, 2014.

GADELHA, Sylvio de Sousa Costa. Governamentalidade neoliberal, Teoria do Capital Humano e Empreendedorismo. Educação \& Realidade, 2009, n. 34: Disponível em: <http://www.redalyc.org/articulo.oa?id=317227054011> Acesso em 23 mai. 2019.

HAN, Byung-Chul. Sociedade do cansaço. São Paulo: Vozes, 2017.

NIETZSCHE, Friedrich. Humano, demasiado humano. São Paulo: Companhia de Bolso, 2005.

PASSETI, Edson. Prefácio. In: FOUCAULT, Michel. Filosofia e biopolítica. Belo horizonte: Autêntica, 2015.

SENNETT, Richard. A corrosão do caráter: as consequências pessoais do trabalho no novo capitalismo. Rio de Janeiro: Record, 2009.

TÁRRES, Joan Pujol; MARTÍNEZ, Marisela Montenegro; MANSANO, Sonia Regina Vargas. Corpos dóceis: novos contornos. In: NALLI, Marcos; MANSANO, Sonia Regina Vargas (orgs.). Michel Foucault desdobramentos. Coleção Estudos Foucaultianos. Belo Horizonte: Autêntica Editora, 2016. p. 215-228.

VEIGA-NETO, Alfredo. Foucault e a Educação. Belo Horizonte: Autêntica, 2007. 